\title{
Continuous ambulatory pulmonary artery pressure monitoring \\ $A$ new method using a transducer tipped catheter and a simple recording system
}

\author{
RICHARD D LEVY, DAVID CUNNINGHAM, LEONARD M SHAPIRO, \\ CHRISTINE WRIGHT, LORNA MOCKUS, KIM M FOX
}

From the National Heart Hospital, London

SUMMARY A transducer tipped catheter and simple recording system were used for the continuous measurement of ambulatory pulmonary artery pressure. The pulmonary artery pressure was recorded on a miniaturised tape recorder and replayed via an optical writer. Pulmonary arterial systolic and diastolic pressures can be analysed on a beat to beat basis. Continuous ambulatory monitoring was performed for a total 288 hours in 13 patients who were undergoing routine investigation for coronary artery disease. There was less than $1 \%$ zero drift and $0.25 \%$ linearity error per full scale pressure. The frequency response of the entire system was flat to $8 \mathrm{~Hz}$ with a linear phase delay. The transducer tipped catheter and a conventional fluid-filled system were used to measure left ventricular and pulmonary artery end diastolic pressures in eight patients. The correlation between the results obtained by the two methods was excellent. This method could be used at any centre equipped for ambulatory electrocardiographic monitoring.

The measurement of pulmonary artery end diastolic pressure provides an accurate assessment of left ventricular end diastolic pressure in the absence of pulmonary vascular disease and mitral stenosis. ${ }^{1-3}$ Until recently recording of pulmonary haemodynamics in man using fluid filled systems was restricted because the equipment was not portable. ${ }^{145}$ Lately, ambulatory pulmonary artery pressure monitoring with fluid filled and transducer tipped catheters in unrestricted subjects has been described. A miniaturised tape recorder was used with the fluid filled catheter and a solid state system was used with the transducer tipped catheter. Data analysis was computerised in both studies. ${ }^{67}$

Fluid filled catheters have many drawbacks, such as difficulty with the localisation of the zero reference point, the requirement for anticoagulation, and

Requests for reprints to Dr R D Levy, National Heart Hospital, Westmoreland Street, London WIM 8BA.

Accepted for publication 7 January 1986 the need to use filtering for data retrieval. ${ }^{8}$ In the previous study in which a transducer tipped catheter was used pressure results were avaraged every thirty seconds. $^{7}$

We describe a simple method for continuous ambulatory pulmonary artery pressure monitoring by means of a transducer tipped catheter and widely available ambulatory monitoring recording equipment.

\section{Patients and methods}

\section{PATIENTS}

Thirteen patients ( 12 male and one female, mean age 52.5 (range 33-70) years) with clinical and electrocardiographic evidence of coronary artery disease were studied while undergoing routine cardiac catheterisation. In eight patients we simultaneously recorded measurements from transducer tipped and fluid filled catheters. The study was approved by the ethics committee and patients gave their informed and written consent. 
CATHETER SYSTEM

We used a polyurethane 6 French NIH type catheter (Gaeltec) with a miniature strain gauge transducer ( $10 \mathrm{~mm}$ long and $2 \mathrm{~mm}$ in diameter) mounted on the tip. The sterile catheter was immersed in saline for at least one hour to stabilise the silicone elastomer covering the transducer.

The catheter was placed in a moist sterile calibration tube. The zero potentiometer on the control box was adjusted to an output of zero $\mathrm{mV}$. The gain potentiometer was adjusted to an output of $40 \mathrm{mV}$ for a pressure of $80 \mathrm{~mm} \mathrm{Hg}$. It was necessary to calibrate each transducer before use because the sensitivity of catheters varied by $5 \%$. The outputs at different pressures were measured on a digital voltmeter and recorded on the Oxford Medilog I tape recorder. Simultaneous recordings were obtained on an oscilloscope and dry silver paper via a Hewlett Packard bioelectric amplifier in the catheter laboratory.

\section{IN VIVO VALIDATION}

The catheter was introduced percutaneously via the right subclavian vein to a proximal pulmonary artery under fluoroscopy. A conventional fluid filled catheter (7 Cournand) was introduced via the right femoral vein and passed into the pulmonary artery in a comparable position. An 8 French pigtail catheter was introduced via the right femoral artery to provide simultaneous recordings of transducer tipped pulmonary artery pressure, fluid filled pulmonary artery pressure, and left ventricular end diastolic pressure. Changes on deep inspiration, expiration, and during a Valsalva manoeuvre were recorded.

After routine coronary angiography the femoral catheters were removed. A $24 \mathrm{~h}$ ambulatory recording of the pulmonary arterial waveform, frequency modulated electrocardiogram (leads CM2 and CM5), and amplitude modulated electrocardiogram (lead CM5) was obtained. After $24 \mathrm{~h}$ the pulmonary artery line was removed and zero drift was measured on the digital volt meter. The catheter was then recalibrated after blood had been washed off the silicone membrane covering the transducer.

\section{RECORDING}

The transducer was driven and demodulated by an electrically isolated Gaeltec preamplifier. The pulmonary artery pressure was recorded on an Oxford Medilog I multichannel miniature tape recorder which was modified by the insertion of an AM4 pressure module. The modulation was adjusted to a maximum applied pressure of $80 \mathrm{~mm} \mathrm{Hg}$. Higher pressures could be recorded but because errors of measurement are quoted on a $\%$ full scale basis, the lower the full scale maximum, the more accurate the recording. Up to $25 \mathrm{~h}$ of pulmonary artery pressure could be recorded at $2 \mathrm{~mm} / \mathrm{s}$ on $\mathrm{C1} 20$ cassettes. An amplitude modulated electrocardiogram can be recorded via this box.

\section{FREQUENCY MODULATED}

ELECTROCARDIOGRAM

Faithful recordings of ST segments were obtained by means of a frequency modulated Oxford Medilog II recording and playback system (frequency response $0.05-40 \mathrm{~Hz}-3 \mathrm{~dB}$ down). Two pairs of bipolar electrodes were applied precordially to record leads CM2 and CM5 and a $24 \mathrm{~h}$ two channel ambulatory recording of the electrocardiogram was obtained. An event marker was linked to both the frequency modulated electrocardiogram and pulmonary artery trace. The system therefore permitted synchronous ambulatory recording of both pulmonary artery pressure and the frequency modulated electrocardiogram.

\section{PLAYBACK}

The tapes were played at 60 times recorded time. The pulmonary artery pressure was demodulated by an Oxford Instruments PM3 unit and the amplitude modulated electrocardiogram was played via a PD2 direct replay amplifier. Both were played via a PB2 playback unit on to a multichannel ultraviolet optical writer. The frequency modulated electrocardiogram was demodulated via a PB4 unit on to the optical writer and was also played on an Oxford Medilog II MA20 scanner.

\section{OPTICAL WRITER}

An ultraviolet SE Laboratories 6008 oscillograph was used. This has a variable playback speed of 25
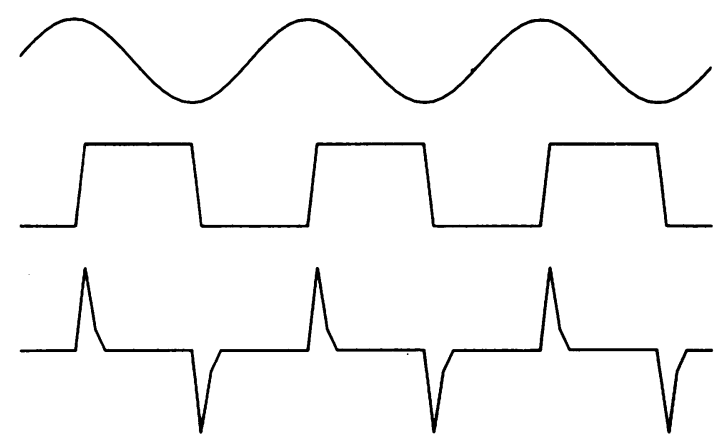

Fig. 1 Simultaneous sine wave and differentiated square wave recordings. Top, sine wave; middle, square wave; bottom, differentiated square wave. The relation of the differentiated square wave to a given point in the sine wave was measured at different frequencies to assess phase delay. 
338

$\mathrm{mm}$ per minute to $4000 \mathrm{~mm}$ per second. The galvanometers have a frequency response up to $1 \mathrm{KHz}$. A speed of $1500 \mathrm{~mm}$ per second represents a real time recorded speed of $25 \mathrm{~mm}$ per second that of a standard electrocardiogram. The pulmonary artery pressure and amplitude modulated electrocardiogram were replayed simultaneously. Event marks on the pulmonary artery trace and the frequency modulated electrocardiogram were used to line up the recordings.

\section{FREQUENCY RESPONSE OF THE MEASURING SYSTEM}

The recording system can be separated into four components: (a) catheter and preamplifier; (b) Oxford Medilog AM4 recording system; (c) Oxford Medilog PB2 playback system; (d) display/writeout system.

\section{Catheter and preamplifier (direct recording)}

The frequency response of the catheter and preamplifier was measured by a "pop" test. 9 The catheter was enclosed in a rigid container with an opening for a three way tap. This was connected to a syringe which had a small hole in it. The system was put under pressure, either by pushing or pulling the
Levy, Cunningham, Shapiro, Wright, Mockus, Fox syringe, with the hole occluded. When the occlusion was removed, a step pressure was applied. Its response was estimated by the degree of overshoot (ringing) of the recorded pressure and the frequency of oscillation of the ringing.

\section{Recording and playback systems}

Amplitude response was measured by the standard method of applying sine waves of constant amplitude but varying frequencies to the system and measuring the output amplitude.

Phase response refers to the phase angle of the output signal after it has passed though the system in relation to the input signal. If a $1 \mathrm{~Hz}$ signal is delayed by $0 \cdot 1$ seconds, it has suffered a phase shift (delay) of 36 degrees (1/10 of cycle). Similarly, if a 5 $\mathrm{Hz}$ signal is delayed by $0 \cdot 1$ second it has a phase delay of 180 degrees, because $0 \cdot 1$ second is half of the cycle length of 0.2 seconds. In general the delay $(d)$ is related to the phase (p) (where (p) is a function of the frequency (f)) by the equation of $\mathrm{p}=\mathrm{d} \times \mathrm{f} \times 360$ degrees. In order to represent faithfully a signal, certain frequency components must not be delayed with respect to others because this will lead to signal distortion. ${ }^{10}$ Therefore, the delay (d) must remain constant. If (d) is a constant, then

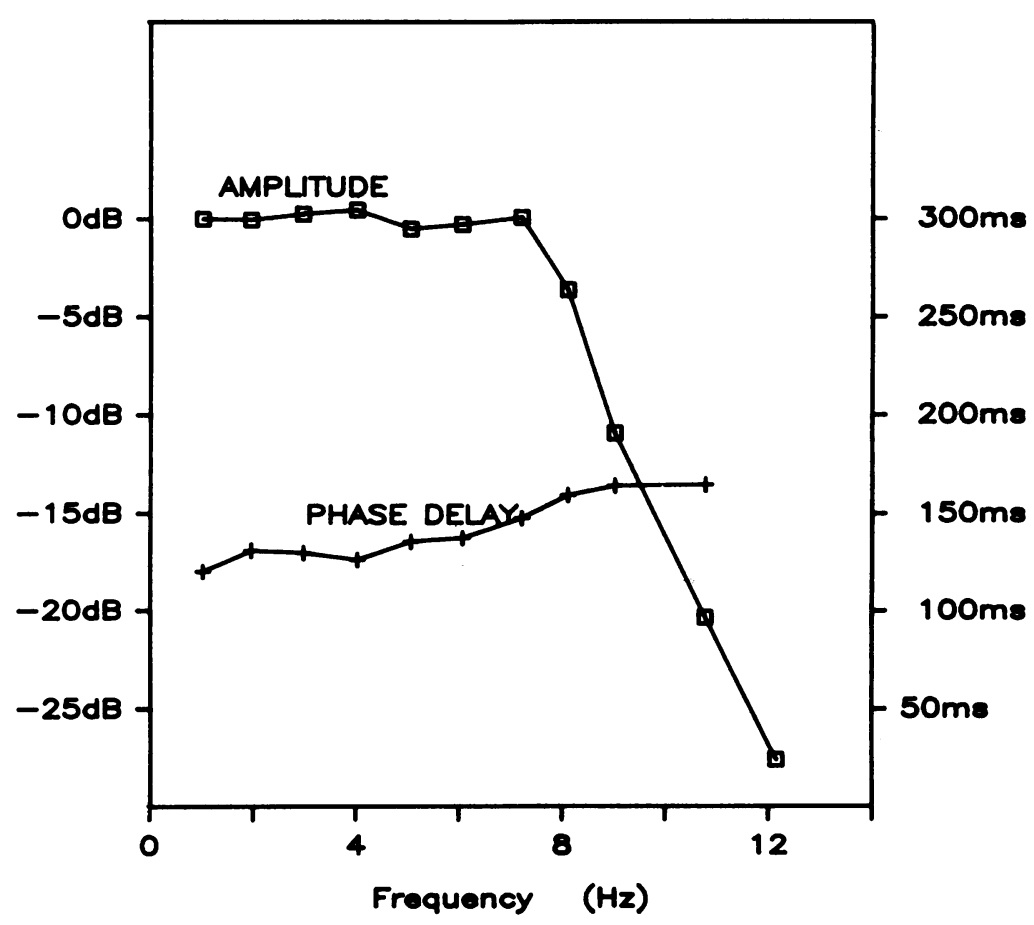

Fig. 2 Amplitude response ( $d B$ ) and phase delay ( $m s$ ) with increasing frequency. The amplitude response was flat to $8 \mathrm{~Hz}$ with a linear phase response over the same frequency range. 
the phase delay ( $p$ ) must be a linear function of frequency ( $f$ ) and therefore $p / f=$ constant. Measurement of phase response is difficult because a reference to the original phase of the signal must be preserved for comparison with the condition signal. A new method was used to measure the phase response of the recording and playback systems. A sine wave of varying frequency was recorded as the pressure channel 1 (Fig. 1). A simultaneous phaselocked synchronised square wave was electronically differentiated (time constant $5 \mathrm{~ms}$ ), attenuated, and then recorded as a series of positive and negative spikes on channel 2 (the electrocardiogram channel). These spikes were identical in shape at all input frequencies and were thus recorded identically, giving a time reference for the phase delay measurements.

\section{Display/writeout system}

In practice the display/writeout system will only impose frequency response limitations if a hot pen recorder is used. In the present study all recordings were made on an SE Laboratories ultraviolet recorder, which has a frequency response far in excess $(>1 \mathrm{kHz})$ of that required for pulmonary artery pressure monitoring.

Fourier analysis-Signals were displayed and averaged on a Gould 1425 digital storage oscilloscope. The oscilloscope had an eight bit accuracy which is equivalent to $-50 \mathrm{~dB}$. Data were analysed off line on a Hewlett Packard 150B microcomputer and a customised fast Fourier transform (FFT) programme. Data were obtained (a) directly from the Gaeltec preamplifier; $(b)$ from a fluid filled pulmonary artery catheter system; and (c) from the recordings played via the replay unit. Waveform configuration and harmonic content were analysed from each source at varying heart rates.

\section{STATISTICS}

Wilcoxon's rank sum test was used for statistical analysis.

\section{Results}

EVALUATION OF THE CATHETER

RECORDING-PLAYBACK SYSTEM

When the catheter pop test was applied to the Gael-

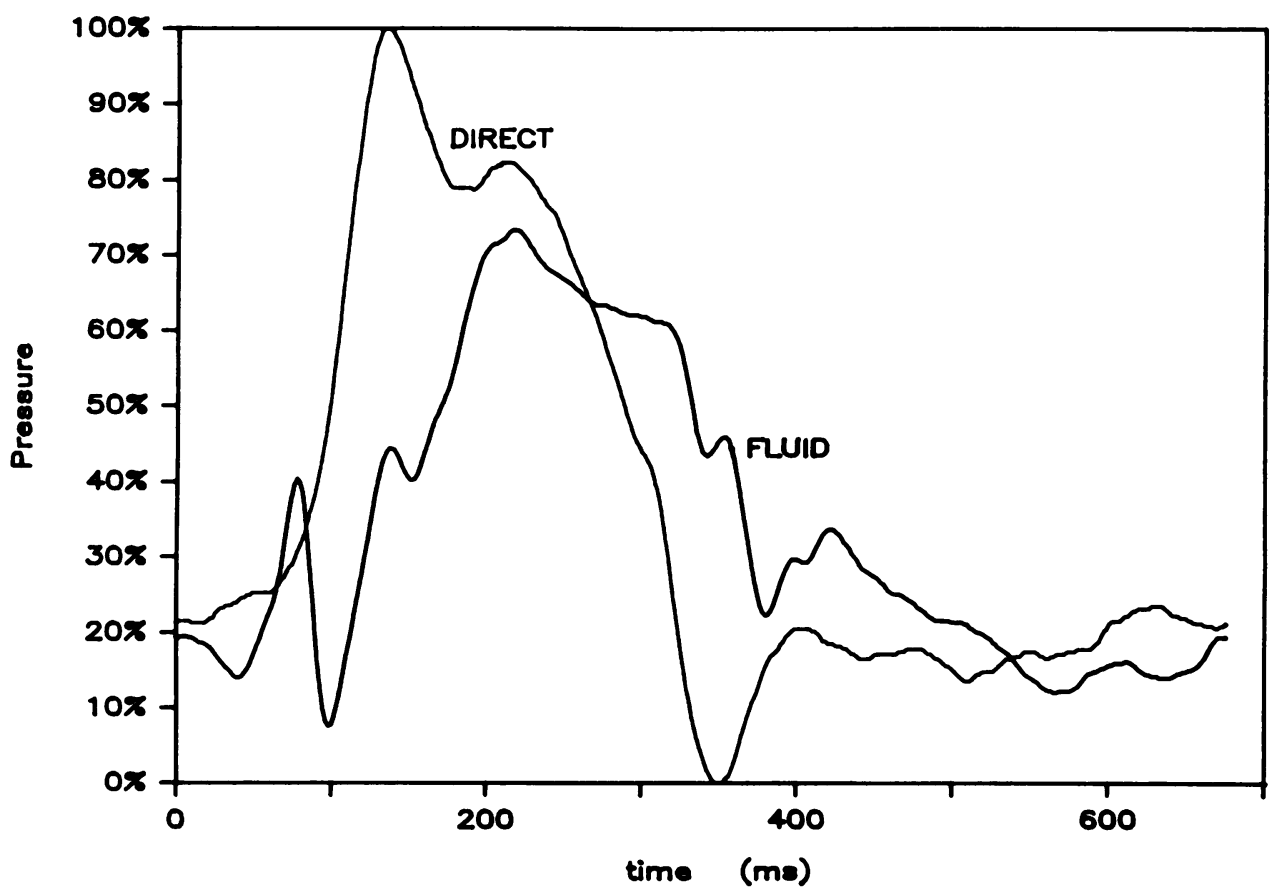

Fig. 3 Simultaneous recordings of transducer tipped and fluid filled pulmonary artery pressure waveform at a constant heart rate of 90 beats per minute. The direct recording is the pressure from the trandsucer tipped catheter and Gaeltec preamplifier. Pressure is expressed as a percentage of the maximum transducer tipped pulmonary artery pressure. 
tec catheter and preamplifier the overshoot was less than $2 \%$ of the applied pressure and the resonant frequency of the system was $285 \mathrm{~Hz}$. Thus there is little or no effect on the frequency response of the overall system due to losses in this element.

The amplitude response of the entire system was flat to $8 \mathrm{~Hz}$. The phase response was linear over the same frequency range (Fig. 2). The phase delay at 8 $\mathrm{Hz}$ differed from that at $1 \mathrm{~Hz}$ by less than $30 \mathrm{~ms}$. Hence, phase distortion was insignificant up to $8 \mathrm{~Hz}$.

Simultaneous recording of direct transducer tipped and fluid filled pulmonary artery pressure showed no difference in the end diastolic pressures, but fluid filled systolic pressure is $25 \%$ less than the Gaeltec systolic pressure and the fluid filled curve is shifted to the right, the recording being delayed by the presence of connecting tubing (Fig. 3).

Fast Fourier transform-The power spectra from direct recordings of transducer tipped and fluid filled catheters were compared together with the amplitude modulated recording (Fig. 4). These were obtained at a constant heart rate of 90 beats per minute. At low frequencies, in the physiological range, the fluid filled system attenuates the amplitude of the frequency content and this affects even the first harmonic. Absolute power is expressed in decibels where $0 \mathrm{~dB}$ is equivalent to $1 \mathrm{~mm} \mathrm{Hg}, 20 \mathrm{~dB}$ to $10 \mathrm{~mm} \mathrm{Hg}$, and $40 \mathrm{~dB}$ to $100 \mathrm{~mm} \mathrm{Hg}$. Flattening out of the curve occurs at $-30 \mathrm{~dB}$. Within the physiological range the power spectrum of the transducer tipped catheter pressure waveform on the Oxford recorder did not differ greatly from the direct recording. Measurements of harmonic power were obtained at different heart rates. At 70 beats per minute $90 \%$ of the harmonic power is expressed below $8 \mathrm{~Hz}$, at 90 beats per minute this is reduced to $80 \%$, and at 150 beats per minute it is $70 \%$. Waveform distortion will increase with increasing heart rate, but this is more intense in higher frequencies and therefore systolic rather than diastolic pressures are distorted. At 150 beats per minute there was a slight increase in higher frequency components.

Signal/noise ratio-The recorded noise level was less than $-50 \mathrm{~dB}$ assessed by amplitude.

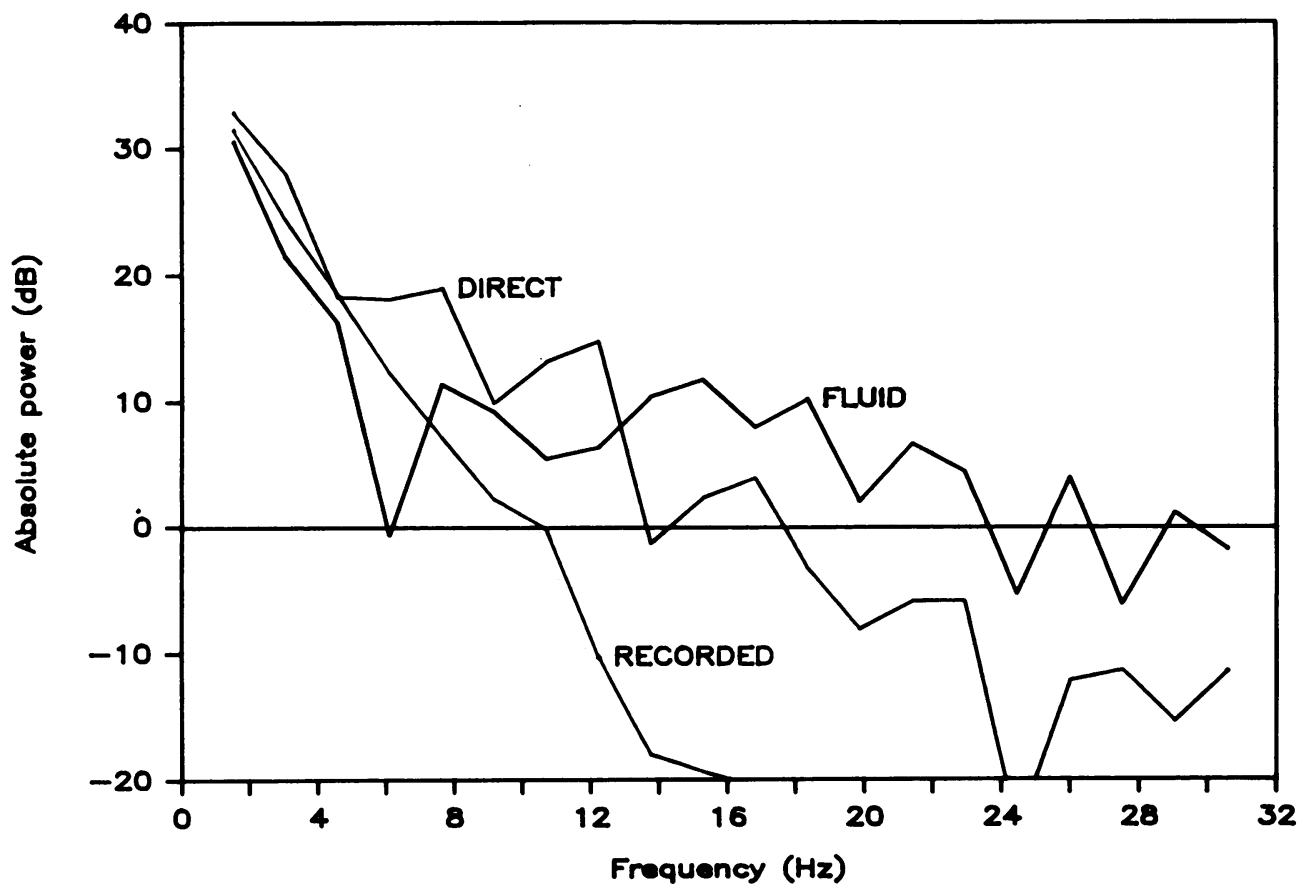

Fig. 4 Fast Fourier transform analysis of direct recordings of pulmonary artery pressure by the transducer tipped and fluid filled catheters together with recordings on the Oxford Medilog system. Absolute power is expressed in decibels. ( $0 \mathrm{~dB}=1 \mathrm{~mm} \mathrm{Hg}, 20 \mathrm{~dB}=10 \mathrm{~mm} \mathrm{Hg}, 40 \mathrm{~dB}=100 \mathrm{~mm} \mathrm{Hg}$ ). These recordings were obtained at a constant heart rate of 90 beats per minute. At low frequencies, in the physiological range, the fluid filled system attenuates the amplitude of the frequency content, and this affects even the first harmonic. The power spectrum of the transducer tipped pulmonary artery pressure waveform on the Oxford recorder did not differ greatly from the direct recording within the physiological range. 


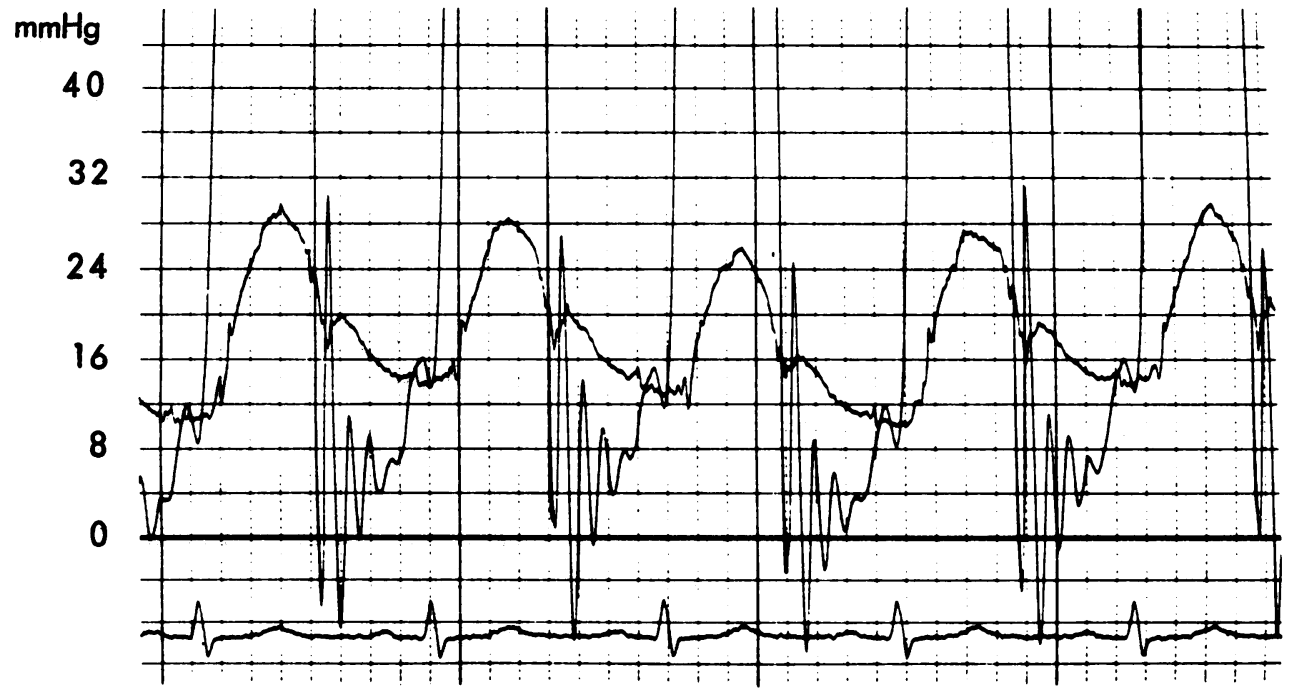

Fig. 5 Left ventricular end diastolic pressure recorded by a fluid filled catheter and pulmonary artery pressure by transducer tipped catheter. Recordings were obtained in the catheter laboratory (paper speed 50 $\mathrm{mm} / \mathrm{s}$ ).

\section{CATHETER SPECIFICATION}

The temperature coefficient of sensitivity was $0.2 \%$ per degree centigrade and the temperature coefficient of zero stability was $0.03 \%$ /full scale/degree centigrade. The sensitivity of the catheter was $5 \mu \mathrm{V} / \mathrm{V} / \mathrm{mm} \mathrm{Hg}$ and linearity was $\pm 0.25 \%$ full scale. A zero drift of $<1 \% /$ full scale $/ 24$ h was achieved after improvements to the elastomer covering the transducer.

CLINICAL EVALUATION

A total of $\mathbf{2 8 8}$ hours of ambulatory pulmonary artery

$\mathrm{mm} \mathrm{Hg}$

\section{0}

30

20

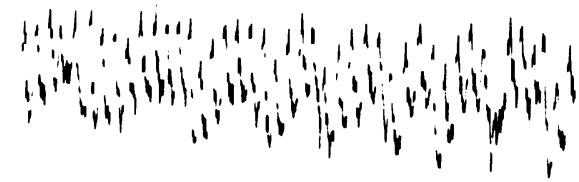

0

Fig. 6 Compressed pulmonary artery trace obtained to show the effects of respiration on the recording. Inspiration reduces and expiration increases the pulmonary artery pressure. This reflects changes in the pleural space. pressure and electrocardiographic recording was obtained in 13 patients with two catheters. The minimum pulmonary artery diastolic pressure was $2 \mathrm{~mm}$ $\mathrm{Hg}$ and the maximum systolic pressure was $80 \mathrm{~mm}$ $\mathrm{Hg}$. Simultaneous measurements of fluid filled and transducer tipped pulmonary artery presure as well as fluid filled ventricular end diastolic pressure were recorded in eight patients. Fluid filled pulmonary artery systolic pressure (mean (SD) 25.9 (7.9) mm $\mathrm{Hg}$ ) was similar to transducer tipped systolic pressure (mean (SD) $27.8(11.2) \mathrm{mm} \mathrm{Hg}$ ). Fluid filled pulmonary artery diastolic pressure (mean (SD) 10.0 $(4.8) \mathrm{mm} \mathrm{Hg}$ ) was similar to transducer tipped diastolic pressure (mean (SD) $11.2(4.6) \mathrm{mm} \mathrm{Hg}$ ) and post " $a$ " left ventricular end diastolic pressure (mean (SD) $10.9(4.8) \mathrm{mm} \mathrm{Hg}$ ). Transducer tipped

\section{$\mathrm{mm} \mathrm{Hg}$}

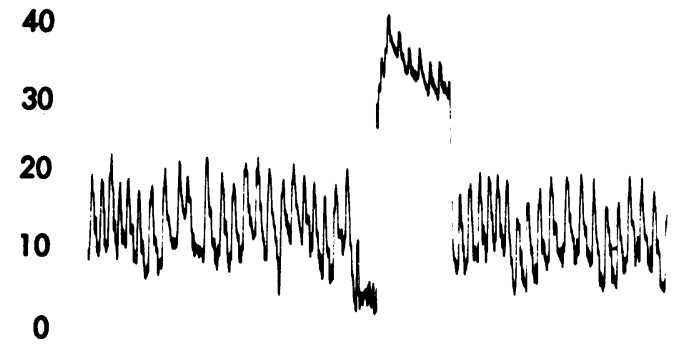

Fig. 7 The effects of a Valsalva manoeuvre on transducer tipped pulmonary artery pressure. 
$\mathrm{mm} \mathrm{Hg}$

30

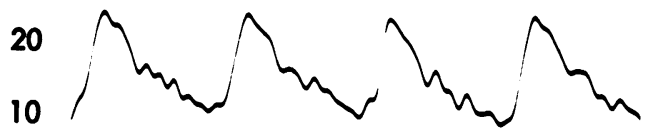

0

Fig. 8 The recorded pulmonary artery pressure waveform played on to the optical writer.

pulmonary artery diastolic pressure correlated well $(r=+0.99, p<0.001)$ with left ventricular end diastolic pressure (Fig. 5).

Figure 6 shows the effect of respiration and Fig. 7 the effect of the Valsalva manoeuvre on pulmonary artery pressure.

The pulmonary artery waveform played via the optical writer (Fig. 8) shows good preservation of the waveform when compared with Fig. 4. All recordings were obtained without the additional use of filters. During exercise in a 33 year old man with three vessel coronary artery disease there was a substantial rise in both the systolic and diastolic pulmonary artery pressures (Fig. 9).

\section{Discussion}

Pulmonary haemodynamics in man were first studied by Cournand and Ranges who modified Forssmann's original techniques of venous catheterisation. ${ }^{112}$ Recordings were limited to only a

$\mathrm{mm} \mathrm{Hg}$

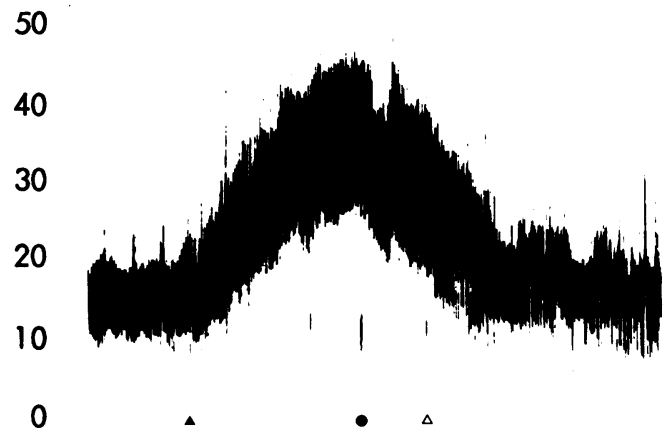

Fig. 9 The effects of exercise on pulmonary artery pressure recorded from a 33 year old man with three vessel coronary artery disease. During exercise there was a rise in the pulmonary artery systolic and diastolic pressures which returned to basal levels when exercise stopped. $\Delta$, start of exercise, $\Delta$, end of exercise ( 8 minutes); $O$, patient pressed event marker for chest pain. few minutes. Prolonged bedside monitoring was possible after catheter modifications, ${ }^{13-15}$ but the equipment was not portable. ${ }^{145}$ Problems with the zero reference point when fluid filled catheters are used have been overcome to some extent by placing the transducer at the level of the catheter tip. ${ }^{7}$ For ambulatory use fluid filled catheters require a transducer-perfusion unit connected to tubing and anticoagulation with heparin. A change in posture from lying to standing altered the zero reference point for fluid filled catheters by about $4 \mathrm{~mm} .^{6}{ }^{16}$ Substandard recordings $(20 \%)$ were due to repeated clotting of the catheter tip and damping of the pressure wave, kinking of the catheter or extension tubing, or both. Fluid filled catheters require a relatively bulky perfusion unit and are liable to artefacts such as overshoot, overdamping, and catheter whip. ${ }^{8}$ They respond satisfactorily to a pressure which remains stationary but have limitations in fidelity when they are used to record varying pressure.

We have analysed the frequency and phase response of the transducer tipped system and have compared the results with a directly recorded fluid filled catheter. For the complete transducer amplifier-record-playback system, the amplitude response was flat to $8 \mathrm{~Hz}$ ( $-3 \mathrm{~dB}$ down). We have preserved the phase of the recorded signal and have shown that the phase response is linear to $8 \mathrm{~Hz}$. Phase delay at $8 \mathrm{~Hz}$ exceeds the phase delay at $1 \mathrm{~Hz}$ by $<30 \mathrm{~ms}$. We have found no appreciable phase distortion up to $8 \mathrm{~Hz}$.

Amplitude response will be constant over a selected band of signal frequencies (the passband) and will fall off at frequencies above and below the passband. The effects of this drop in amplitude response at low frequencies will be to increase artificially baseline stability at the expense of faithful reproduction of low frequency components (for example the diastolic period of a pressure waveform). For most pressure measuring systems, including that used in the present study, the low frequency response is adequate for faithful signal reproduction. At high frequencies, however, the drop in amplitude response (gain) of the system selectively attenuates the high frequency components of the waveform. If the high frequency response is severely limited then the greatest effect on the waveform will be on its fastest moving components-that is the upstroke-and thus the systolic pressure may be underestimated. The diastolic pressure is less likely to be affected by high frequency attenuation. As the heart rate increases from 70 to 150 beats per minute there is a slight decrease in harmonic power $(20 \%)$ below $8 \mathrm{~Hz}$. We have found that at 70 beats per minute $90 \%$ power is 
expressed below $8 \mathrm{~Hz}$ and this accords with other studies. ${ }^{17}$ The loss of harmonic power with increasing heart rate is associated with some waveform distortion, but this tends not to affect diastolic pressure. The fluid filled system attenuates the amplitude of the frequency content (Fig. 3) including the first harmonic. This low frequency attenuation is greatly improved with a transducer tipped catheter with little loss in the Oxford recording.

Nathan et al first described continuous ambulatory pulmonary artery pressure monitoring with a transducer-tipped catheter. ${ }^{7}$ The recording system was complex and expensive because it used a solid state system and computer analysis. The pulmonary artery pressure was averaged over $30 \mathrm{~s}$, not beat to beat. The catheter required immersion in saline for five hours in order to minimise zero drift. We found that with improved elastomers this time could be reduced to one hour.

We have confirmed that in the absence of pulmonary vascular disease and mitral stenosis measurement by transducer tipped catheter of pulmonary artery end diastolic pressure correlates closely with left ventricular end diastolic pressure (Fig. 3). ${ }^{1-3}$ If they are not handled carefully the transducer membranes are susceptible to damage that results in zero drift.

Most complications reported with long term pulmonary artery catheterisation with Swan-Ganz catheters have been due to impaction of an inflated balloon in a distal branch of the pulmonary artery. ${ }^{1819}$ In two patients in our study the transducer tipped catheter tip changed position and became slightly wedged. In one case this occurred after $18 \mathrm{~h}$ and in the other after $24 \mathrm{~h}$. This had no apparent deleterious effects.

We have described a system of continuous pulmonary artery pressure recording in which every beat during periods of interest can be recorded and replayed. Thus most of the drawbacks of fluid filled catheters and the limitations of solid state transducer tipped systems have been overcome. This method could be used in any centre equipped for ambulatory electrocardiographic monitoring. The technique may be used to study the pathophysiology and treatment of coronary artery disease and cardiac failure as well as primary and secondary pulmonary hypertension.

We thank the Clinical Research Committee of the National Heart and Chest Hospitals for financial support.

\section{References}

1 Scheinman M, Evans GT, Weiss A, Rapaport E.
Relationship between pulmonary artery end diastolic pressure and left ventricular pressure in patients in shock. Circulation 1973; 47: 317-24.

2 Kaltman AJ, Herbert WH, Conroy RJ, Kossman CE. The gradient in pressure across the pulmonary vascular bed during diastole. Circulation 1966; 34: 377-84.

3 Rackley CE, Russell RO Jr, Moraski RE, Mantle JA. Recent advances in haemodynamic studies in patients with acute myocardial infarction. In: Yu PN, Goodwin JF, eds. Progress in cardiology. vol 5. Philadelphia: Lea and Febiger, 1976: 201-26.

4 Ratshin RA, Rackley CE, Russell RO Jr. Haemodynamic evaluation of left ventricular function in shock complicating myocardial infarction. Circulation 1972; 45: 127-39.

5 Dalen JE. Bedside haemodynamic monitoring. $N$ Engl f Med 1979; 301: 1176-8.

6 Ikram H, Richards AM, Hamilton EJ, Nicholls MG. Continuous recording of pulmonary artery pressure in unrestricted subjects. Br Heart $\mathcal{F}$ 1984; 51: 421-6.

7 Nathan AW, Perry SG, Cochrane T, Banim SO, Spurrell RAJ, Camm AJ. Ambulatory monitoring of pulmonary artery pressure. A preliminary clinical evaluation. Br Heart 9 1983; 49: 33-7.

8 Grossman W. Pressure measurement. In: Grossman W, ed. Cardiac catheterisation and angiography. 2nd ed. Philadelphia: Lea and Febiger, 1980: 103-15.

$9 \mathrm{McD}$ onald DA. The design of manometers. In: Blood flow in arteries. 2nd ed. London: Edward Arnold, 1974: 174-208.

10 Tayler DI, Vincent R. Artefactual ST segment abnormalities due to electrocardiographic design. Br Heart $\mathcal{F}$ 1985; 54: 121-8.

11 Cournand A, Ranges HA. Catheterisation of the right auricle in man. Proc Soc Exp Biol Med 1941; 46: 462-6.

12 Forssmann W. Die Sondierung des rechten Herzens. Klin Wochenschr 1929; 8: 2085-7.

13 Bradley RD. Diagnostic right heart catheterisation with miniature catheters in severely ill patients. Lancet 1964; ii: 941-2.

14 Fife WP, Lee BS. Construction and use of self-guiding right heart and pulmonary artery catheter. $f$ Appl Physiol 1965; 20: 148-9.

15 Swan HJC, Ganz W, Forrester J, Marcus H, Diamond G, Chonnette D. Catheterisation of the heart in man with use of a flow-directed balloon-tipped catheter. $N$ Engl f Med 1970; 283: 447-51.

16 Verel D, Grainger RG. Cardiac catheterisation and angiography. 3rd ed. Edinburgh: Churchill Livingstone, 1978: 8-17.

17 Milnor WR. Pulmonary haemodynamics. In: Bergel DH, ed. Cardiovascular fluid dynamics, vol 2. London and New York: Academic Press, 1972: 299-340.

18 Foote GA, Schabel SI. Pulmonary complications of the flow directed balloon-tipped catheter. $N$ Engl $\mathcal{F}$ Med 1974; 290: 927-31.

19 Sise MJ, Hollinsworth P, Brimm JE, Peters PM, Virgilio RW, Shackford SR. Complications of the flow directed pulmonary artery catheter: a prospective analysis in 219 patients. Crit Care Med 1981; 9: 315-8. 